\title{
Elaboration likelihood model: A missing intrinsic emotional implication
}

\section{Jon D. Morris}

is a professor in the Department of Advertising, College of Journalism and Communications, University of Florida. He began teaching at the university in 1984. Previous to his academic positions, he worked in the advertising agency business. He began his advertising career in 1968, and has worked for several agencies, including Nicholson-Morris, Louisville, KY, and Doyle Dane Bernbach and Dancer Fitzgerald Sample, New York, NY. He earned his PhD from the University of Florida. His research has appeared in the Journal of Advertising Research, Educational Technology, the International Journal of Instructional Media, and in the Proceedings of the American Academy of Advertising, among others. Over the past few years, he has been developing a model (AdSAM) for analysing emotional response to marketing communications.

\section{ChongMoo Woo}

is a doctoral student majoring in advertising in the Department of Advertising at the University of Florida. He received a BA and MA, both in advertising and public relations from the Chung-Ang University, Seoul, South Korea, and an MA in advertising from the University of Florida. During the programme of study, he has completed course work toward an MA in statistics and has published in the Journal of Advertising Research, the Journal of Current Issues and Research in Advertising, Advances in Consumer Research, and others.

\section{A. J. Singh}

completed his BA in Commerce in 1994 at the University of Mumbai and then obtained an MA in economics from the same university in 1997. He received his MA in mass communication with a specialisation in advertising in May 2003 from the University of Florida. He is currently employed in Delhi, India, as Account Manager and Producer for the Online and Interactive Department of the Discovery Channel.

Jon D. Morris

University of Florida

College of Journalism and

Communications

PO Box 118400

Gainesville, FL 32611-8400

USA

Tel: +1 (352) 2196000 ;

+1 (352) 392 0443:

E-mail: jonmorris@ufl.edu

Abstract The Elaboration Likelihood Model (ELM), developed by Petty and Cacioppo, proposed two routes to attitude change: central and peripheral. The central route emphasises a high relevance of the message to the individual. In the peripheral route, the individual concentrates on heuristic cues like attractive expert sources and number rather than the content of arguments employed by the message to process the message. If these cues produce an attitude change, this change is likely to be shorter lasting and unpredictable of that individual's behaviour. Hence, the cognitive (central) aspect of the ELM overshadows its affective (peripheral) aspect, and the underlying suggestion of this model is that an attitude change is mostly reached through cognition as opposed to emotion. This study attempts to show that the emotional aspect is as important as the cognitive aspect. The basis for this conclusion is that even as an individual processes a message cognitively, that cognition has an emotional core. In addition, there is a possibility that content processing (elaboration) gives rise to emotions and that this leads to a longer-lasting change in attitudes.

Keywords: Elaboration Likelihood Model, cognition, emotion, structural equation modelling, consumer behaviour, Self-Assessment Manikin, PAD

(pleasure-arousal-dominance)

\section{INTRODUCTION}

The roots of persuasion are embedded deeply in the human psyche as well as in human history. It was approximately 2,400 years ago that Aristotle clearly identified the three main aspects of the 
persuasion situation: source, audience and message content.

Given this support for the long history of persuasive processes, it is surprising that it was only 60 years ago that any sort of systematic research attention was applied to the study of persuasion. Carl Hovland, a Yale psychologist, has been attributed with the creating 'the modern experimental study of persuasion'. ${ }^{1}$ Systematic persuasion research, however, can be linked to media effects research that began with Walter Lippmann ${ }^{2}$ and Harold Lasswell. ${ }^{3}$

The problem with this research was that it was based on anecdotal evidence and not empirical research. ${ }^{4}$ Then, in the 1940s and 1950s, there was a shift in researchers' thinking, as evidence increasingly pointed to an indirect effects model of persuasion. Hyman and Sheatsely ${ }^{5}$ suggested that a mere increase in message flow could not achieve persuasion and that effective message dissemination requires consideration of specific psychological barriers. This led to the idea of a 'two-step' flow of communication as suggested by Katz and Lazarsfeld, ${ }^{6}$ who argued that the media tend to influence opinion leaders, who in turn influence the public.

The persuasion debate was then brought to another level by the research of Hovland et al., ${ }^{7}$ who documented the importance of different factors in persuading people to accept a proposition. Subsequent research on persuasion has focused on the moderating variables, such as knowledge and beliefs, to develop contemporary models of persuasion.

As with any important human process, the presence of both affect (or feelings) as well as information processing can be felt permeating the research on persuasion. Although persuasion researchers are split into the camps of cognition and affect, they all agree that 'the most distinctive and indispensable concept in contemporary social psychology, is that of a variable known as attitude. The importance of the attitude concept stems from the fact that it is believed to be a mediating variable for knowledge acquisition as well as behavioural change. ${ }^{9}$

Given the importance of attitude and attitude change in mediating behaviour, many social psychologists and sociologists have tried to define attitude. As a result, there are a multitude of definitions of this term. ${ }^{10,11}$ Social psychologists, however, reached a sort of consensus that the term should be used to refer to 'a general and enduring positive or negative feeling about some person, object or issue'. ${ }^{12,13}$ The study of attitude change has become a source of great debate and assumed primary focus for persuasion researchers.

A change in affect (negative or positive) as a result of a change in commercial stimuli has recently been shown to be linked to behaviour and behavioural changes, ${ }^{14}$ contradicting a previous number of studies that questioned the ability of affect to predict behaviour. ${ }^{15}$ In fact, the mid-1970s were filled with disillusionment towards the affective attitude concept. As a result, in that period, there was a sharp decline in the study of attitudes by social psychologists, ${ }^{16}$ even though Fishbein and Ajzen ${ }^{17-20}$ have been able to conclude, with confidence, that attitude and behaviours are strongly linked.

According to Fishbein and Ajzen, what distinguishes attitude from other concepts is its strongly affective nature and that 'affect is the most essential part of the attitude concept'. ${ }^{21}$ A strong link between attitudes and subsequent behaviour had already been examined, albeit cognitively, by Petty and Cacioppo in their Elaboration Likelihood Model (ELM). ${ }^{22}$ 
This lack of support for affect as a dominant figure in the creation of persuasion most likely led to the assertion in the $\mathrm{ELM}^{23}$ that there are two routes to attitude change: central and peripheral. The central route emphasises high relevance of the message to the individual. The greater the relevance and the more interest that the individual shows in the subject of the message, usually a product, the higher the chances that they will think or elaborate on the message. Another aspect of the central route is that it deals with the message content - text, words, written material used in the message - as opposed to the peripheral route that deals with the message cues - colour use, people/lifestyle depiction, visuals, etc. ${ }^{24}$ This thinking seems to eliminate the possibility that emotional processing may be as important in the central route as in the peripheral route. Why does cognitive processing have to be void of emotional influence?

The peripheral route is said to be the path taken when the message had little or no relevance to its receiver. ${ }^{25}$ The individual concentrates on heuristic cues such as attractive expert sources and numbers rather than the content of arguments employed by the message in order to process it. According to the ELM, if these cues produce an attitude change, this change is likely to be shorter lasting and unpredictable of that individual's behaviour. ${ }^{26}$ Hence, the information processing (central) aspect of the ELM overshadows the affective (peripheral) aspect, and the underlying suggestion of this model is that an attitude change is mostly through information processing as opposed to emotion.

Given recent findings, however, highlighting the importance of affect over information processing in predicting behaviour, ${ }^{27}$ the current study was undertaken to examine the central route to persuasion and the role of affect versus cognition. The basis for this conclusion is that even as an individual processes a message cognitively, the cognition has an emotional core.

\section{CONCEPTUALISATION}

\section{Emotion: The affective neuroscience}

The role of emotion was largely ignored until the 1970s; indeed, there was a prevailing opinion that emotions, for the most part, 'disrupt and disorganise behaviour and are primarily a source of human problems'. ${ }^{28}$ Naturally, there were scientists who opposed the prevailing view regarding emotions and supported the idea that emotions played a central role in behavioural changes that were said to represent learning. ${ }^{29}$ Despite this support, emotion remained an absent entity in the classic works of cognitive science and cognitive neuroscience. ${ }^{30}$

Recent research conducted in the field of affective neuroscience elevated emotions from the status of mere physiological responses, by identifying regions of the brain - specifically, the amygdala, ventromedial prefrontal, brain-stem nuclei, hypothalamus and basal forebrain - as areas responsible for processing different emotions to varying degrees. ${ }^{31}$ Most of these regions are subcortical, referring to their location below the cerebral cortex, an area that is of primary importance to cognitive neuroscientists. The proposition cited in the ELM, stating that information processing is a separate and more direct route to persuasion than affect, appears to be contradicted by these physiological findings.

The limbic, or primitive/subcortical brain system, was hypothesised to be the seat of emotion and the cortex, or the higher brain, the seat of cognition; 
however, neuroscientific experiments disproved this theory. ${ }^{32}$ Certain subcortical structures that were previously thought only to regulate emotion have now been shown to be intimately connected to cognition as well (ie hippocampus for memory). By contrast, certain cortical structures that were exclusively the province of cognition (ie the prefrontal cortex) have been shown to be involved in emotional processing. ${ }^{33-35}$

Neuroscientists have also been attempting to solve one of the most enduring controversies of social science - the primacy hypothesis. This hypothesis attempts to identify the primacy of affect over cognition or vice versa. Joseph Ledoux's experiments support the primacy of affect hypothesis as expounded by Zajonc. ${ }^{36}$ Ledoux's experiments involving fear conditioning in rats conclusively showed that fear, one of the basic emotions, is processed in the almond-shaped, subcortical structure of the brain, the amygdala. The amygdala not only processes the emotion of fear, but also does so without the aid of conscious thought. ${ }^{37}$

Antonio Damasio is another pioneer in the field of affective neuroscience. His work with patients with disturbed emotions, as a result of frontal lobe damage shows that, although individuals may have complete control over their thought or logical processes, they do not have the same control over their emotions, and in fact their very survival is endangered. ${ }^{38}$ In addition, Damasio experimentally proved that reasoning and decision making cannot exist without the accompaniment of emotion. In studies of patients who were entirely rational until the time that neurological damage affected areas of the brain involved in emotional processing, it was seen that not only did these individuals lose a certain class of emotions, they also lost the ability to make rational decisions. ${ }^{39}$

Affective neuroscience, at the turn of the millennium, has firmly entrenched itself in the brain. Drawing from the findings of forerunners such as Damasio and Ledoux, researchers have established the fact that the brain circuitry of emotion and cognition is not separate. ${ }^{40}$ Data have shown that no parts of the brain are dedicated exclusively to cognition or affect. Emotion evolved to facilitate an organism's adaptation to the complex challenges it faced during its past, ${ }^{41}$ and it is hard-wired in the brain. ${ }^{42}$ It has been conclusively shown that the architecture of the brain does not honour the age-old concept of segregation of cognition and affect. Most compellingly, cognition has been shown to be rudderless without emotion, and studies in cognitive neuroscience and behavioural science cannot be conducted without taking emotion into account. ${ }^{43}$

\section{ELM: The cognitive response hierarchy}

Since the 1950s, a great deal of research has been conducted to understand, describe and predict consumers' attitudinal responses to advertising. ${ }^{44}$ According to Petty and Cacioppo, ${ }^{45}$ most theories of attitude change that exist as a result of research conducted in the 1950s can be grouped into seven major approaches, namely:

- conditioning and modelling approaches that focus on the direct effects of rewards and punishments;

- the message-learning approach that focuses on an individual's attention to, understanding and acceptance of a persuasive message;

- judgmental approaches that focus on past experiences' impacts on attitudinal judgments; 
- motivational approaches that examine the relationship between human motives and attitudinal changes;

- attributional approaches that focus on the relationship between inferences about self or others and attitudinal changes;

- combinatory approaches that focus on the integration of information into an overall attitude; and

- self-persuasion approaches that focus on self-generated information in the presence or absence of a persuasive message.

Although these seven approaches utilise different variables and different processes, 'they really seem to indicate that there are only two fundamentally different "routes" to changing a person's attitudes'. ${ }^{46}$ These two routes, central and peripheral, form the basis of the ELM, which, according to its authors, is an attempt to outline a framework that 'takes one step toward a general theory of attitude change'. ${ }^{47}$

The ELM belongs to a family of models described as the response hierarchy models. These models attempt to depict the changes that a consumer undergoes when they move from a state of relative unawareness about a certain brand or product to relative awareness and then, finally, to purchase intentions/behaviour. ${ }^{48}$ One of the first (and perhaps the best known) response hierarchy models was the 'hierarchy of effects' (HOE) model. ${ }^{49}$ According to Lavidge and Steiner, ${ }^{50}$ there are six steps followed by consumers before actual purchasing, namely:

- complete unawareness of the existence of a product or service;

- mere awareness of the existence of the product or service;

- knowledge about what the product offers;
— favourable attitudes toward the product;

- preference over alternative products; and

- conviction that the purchase will be wise.

The formulation of these six steps then laid the basis for further models and research studies on how advertising communication works (eg Krugman, ${ }^{51}$ Houston and Rothschild, ${ }^{52}$ Vaughn, ${ }^{53}$ Petty et al., ${ }^{54}$ etc). These hierarchy models have proved to be conceptually useful in addition to being accepted by many advertising academicians and practitioners. ${ }^{55}$ Among the many models spawned by the response hierarchy, the ELM received special attention because of its cognitive base and widespread usage in a variety of disciplines.

Although a number of cognitive theories of attitude change have been developed over the years, the one that provides the foundation for the ELM is the communication/persuasion matrix model. ${ }^{56,57}$ The McGuire model contains a few drawbacks ${ }^{58,59}$ that have purportedly been addressed by the cognitive response theory developed by Greenwald $^{60}$ and Petty et al. ${ }^{61}$ The cognitive response theory, too, has had its share of drawbacks. The major criticism is that it focuses only on individuals who process messages actively and failed to take into account individuals who do not think actively about the information they receive. ${ }^{62}$ The ELM seems to fill this gap in the cognitive response theory by suggesting that there are two routes to persuasion: (1) the route taken by individuals who think actively about information in a message - that is, the central route - and (2) the route taken by individuals who do not think actively about the informational content of a message - that is, the peripheral route.

The central route emphasises 
cognitive/effortful thinking and minimal emotional involvement in processing messages. This path to persuasion involves 'paying careful attention to the relevant information in the message and relating that information to previous knowledge stored in memory and generating new implications for the information'. ${ }^{63}$ This process of cognitive responses to a message is considered the likelihood that an individual will elaborate on a particular message. This route, however, demands that a message has high relevance to a particular individual, and this individual should have the motivation and ability to process the arguments present in the message. Individuals who travel this route may be referred to as 'cognitive elaborators'.

The peripheral route is almost the exact opposite of the central route to persuasion. Individuals who travel this route are referred to as 'cognitive misers ${ }^{64}$ and process messages based on simple affective cues such as source attractiveness and message length. The individual takes this route in a low relevance/low motivation situation and processes the message at a very heuristic level by observing the audio-visual cues present in the message and without thinking too much of the arguments present therein. Hence, the peripheral route is characterised by 'an absence of effortful message elaboration' and the attitude formations and changes engendered by this route are 'less accessible, persistent, resistant and predictive of behaviour' as compared with attitudes developed by the central route. $^{65}$

\section{Emotion and ELM}

As a model of cognitive responses, the ELM attempts to account for the presence of affect in the process of attitude formation and change by keeping it on the periphery of that process. The model was developed at a time when the role of emotions in communication was not clearly understood by social scientists. This thinking seems to eliminate the possibility that emotional processing may be as important in the central route as in the peripheral route. Why does cognitive processing have to be void of emotional influence?

The resurgence of interest in emotions ${ }^{66-69}$ has given rise to new research and provided eye-opening results of the role that emotions play in an individual's life. Hence, it becomes necessary to re-examine the ELM in the light of these findings and wonder whether affect should be kept at the periphery of such a widely used model of attitude formation and change or moved to centre.

The peripheral route was said to be the path taken when the message had little or no relevance to its receiver. ${ }^{70}$ The individual concentrates on heuristic cues such as attractive expert sources and numbers rather than the content of arguments employed by the message in order to process it.

Current research indicates that emotional reactions influence both systematic and heuristic processing. It shows, for example, that positive emotions influence peripheral information processing while negative emotions influence central processing. ${ }^{71-74}$

Researchers have then gone a step further, claiming that there may be no central or peripheral cues and that the two routes to persuasion can interact with each other with one route dominating in the face of contradictory information and both routes occurring concurrently when the provided persuasive information does not contradict the attitude structure of an individual. ${ }^{75}$ 
Subsequent research supported this line of thought, and while investigating the influence of print advertisements on the affective and cognitive responses of adolescents, Edens and McCormick ${ }^{76}$ discovered that 'many adolescents were unable to detect the explicit claim of an advertisement yet maintained that the ad "made sense", which suggests that peripheral visual (or emotional) information becomes the central message'. Such research, therefore, provides a strong case for placing affect at the centre of the ELM.

\section{Research questions}

Advertising rests on the fundamental belief that a consumer can be persuaded to purchase a given product. ${ }^{77}$ The ELM is a theory of persuasion that is widely used in a disparate array of disciplines to explain persuasion as a result of cognition. It is clear from a review of the model, that the ELM has a cognitive base. $^{78}$ What is also clear is that the model dispenses of affect as 'a simple peripheral cue' that causes a less persistent change in attitude and concentrates on promoting cognition as the main force behind a longer-lasting change in attitude. ${ }^{79}$

The existing theory of affect gives this study a twofold purpose: to examine the ELM from an emotional standpoint and to determine whether emotions are a component in the central route to persuasion, thus showing that a change in attitude and the resultant behaviour is due to affective as well as cognitive drives.

$\mathrm{RQ}_{1}$ : Would cognitive elaborators display positive emotional response to advertising, and, if so, would this response be significantly different from cognitive misers?

$\mathrm{RQ}_{2}$ : What has a greater effect on the purchase intention of a consumer in the attitude change process outlined by the ELM: cognition or affect?

$\mathrm{RQ}_{3}$ : Does emotion play a more central role in the attitude change process outlined by the ELM?

\section{METHOD}

\section{Research design}

Following the process outlined in the ELM, where the direct route to persuasion was defined as a focus of attention on the product's features and benefits and the peripheral route is defined as a focus on the executional variables of the communications, the respondents in this study were split into two groups, labelled cognitive elaborators or cognitive misers. The two groups were formed on the basis of the participants' spontaneous reactions to two car advertisements. If the spontaneous first reaction contained a reference to the executional variables - that is the elements of the commercial such as the setting or characters - their reaction classified the respondents as cognitive misers. Likewise, if the first reaction contained reference to the product and its features, then the respondents were classified as cognitive elaborators. By definition, the cognitive elaborators would focus on the information and have minimal emotional involvement while the cognitive misers would focus on the execution with an absence of effortful elaboration. The data sets obtained from these two groups were analysed to determine whether cognition or affect dictated the intended future purchasing behaviour of the respondents. This, in turn, helped to determine whether it was justified to keep emotion at the periphery of the attitude-change 
process as defined by the ELM or give it a more central role.

Therefore, the hypotheses addressed by the study were:

$\mathrm{H}_{1}$ : The emotional response (ER) of the cognitive elaborators as measured by the $\operatorname{AdSAM}^{\circledR}$ emotional response pleasure, arousal and dominance (PAD) scale will be significantly greater than that of the cognitive misers. Thus, Elab ER $>$ Miser $_{\mathrm{ER}}$.

$\mathrm{H}_{2}$ : Emotional response and purchase intent are directly related to each other. Thus, the higher the PAD score, the higher the purchase intent of that group.

To evaluate the effectiveness of a mini-campaign of two automobile advertisements that depicted a mid-size luxury sedan, mall intercepts were conducted in the cities of Atlanta, Chicago, Cleveland, Dallas, Los Angeles, Melbourne, Minneapolis, New York, Orlando, Philadelphia, Phoenix and San Francisco. The participants were paid to watch a series of advertisements and then to respond to questions about them.

The copy testing of the car commercials intended to measure the performance of each commercial on the basis of four key dimensions: impact/brand name registration, comprehension, evaluation and intended response. The participants were exposed to a clutter of seven commercials, and the car commercial was placed in the centre of the clutter. The idea was to test: recall through clutter and main ideas through clutter. In order to test a number of variables, including spontaneous comments (thoughts and feelings), emotional response (AdSAM) and purchase intention, an isolated re-exposure to the car commercial(s) was then conducted.
The data sets that were generated as a result of this testing were then examined with special emphasis on the variable of spontaneous comments. The questions that isolate this variable for analysis were: What went through your mind as you watched this commercial? What were your thoughts as you watched it? In the given data sets, the reactions to this question were evaluated and recoded as cognitive elaborators and cognitive misers. AdSAM ${ }^{\circledR}$, a non-verbal measure that assesses emotional response, was used in the questionnaire in order to gauge the emotional reactions of the participants on three dimensions: pleasure, arousal and dominance. The emotional responses to the car commercial(s) generated by $\operatorname{AdSAM}^{\circledR}$ were then used in the analysis of the recoded data with the purchase intention. Based on the internal data of the motor company that sponsored the research, the time frame of the purchase intention was set to be two years. The participants were asked to report their intention to purchase a new vehicle within the next two years. Additional qualifications included demographics such as age, annual household income and education, and behaviours such as driving frequency (see sample).

\section{Coding procedure}

Three coders (two males and one female) independently coded the spontaneous comments variable in accordance with the following set of rules. First, if the comments of a participant were related to the product and its features, that reaction would be considered a cognitive response and the participant would be placed in a group labelled cognitive elaborators. Secondly, if the spontaneous comments of a participant were related to the execution/setting of the commercial, the response would be considered non-cognitive and the 
participant would be placed in a group labelled cognitive misers.

Intercoder reliability was calculated using Holsti's formula ${ }^{80}$ for reliability among coders:

$$
\text { Reliability }=3 \mathrm{M} / \mathrm{N}_{1}+\mathrm{N}_{2}+\mathrm{N}_{3} \text {. }
$$

The $M$ denotes the number of coding decisions the coders agree on, whereas $\mathrm{N}_{1}, \mathrm{~N}_{2}$ and $\mathrm{N}_{3}$ represent the total number of coding decisions made by each of the three coders. The three coders compared the results of their coding for the sample. The inter-coder reliability was found to be 99 per cent.

\section{Sample}

The research sample was obtained from a large marketing communications firm and was part of a comprehensive copy test. A total of 254 participants (50 per cent male and 50 per cent female) from major US cities were extracted for the test of the car advertisements.

Participants in the study were screened to ensure that the sample was involved in the car buying and had motivation as well as ability to process the given persuasive communication message of high involvement/thinking product. ${ }^{81}$ These qualifications were: age 35-54 years (50 per cent 35-44 years, 50 per cent $45-54$ years), with a household income of $\$ 50,000+$ and a minimum of some college education. They needed to be a principal driver and primary/shared decision-maker of a 1992 or newer vehicle (not a van or sport utility), bought new, who intended to purchase a new, not used, vehicle from a qualifying vehicle set within the next two years. They had to be willing to consider both domestics and imports and qualify on a key psychographic battery.

As noted earlier, the socio-demographics were used to screen qualified participants towards whom the car advertisements were targeted. They were not measures of involvement.

According to the ELM, it is motivation that essentially determines an individual's choice of the central or the peripheral route to persuasion. ${ }^{82}$ Although there is a strong link between motivation and involvement, there is evidence that involvement's impact on motivation is limited. It has been found that '[i]n most instances, consumers experience situational (temporary) involvement with an offering or activity' rather than enduring involvement. ${ }^{83}$ Additionally, Cacioppo et al. argued that ' $[\mathrm{t}]$ he fact that the situational factors that have been used to manipulate the extent to which attitudes are based on issue-relevant thinking sometimes account for only a small portion of variance is theoretically due, in part, to systematic individual differences among people in their desire to engage in issue-relevant thinking when they formulate their attitudes'. ${ }^{84}$ Further, they argued that one of the systematic individual differences is need for cognition and individuals low in need for cognition are cognitive misers. ${ }^{85}$ Without measuring or controlling involvement, these researchers ${ }^{86}$ examined the persuasion routers travelled by individuals low in need for cognition (cognitive misers) and high in need for cognition (cognitive elaborators) and reported a moderating effect of need-for-cognition on argument quality's influence on attitude.

\section{Instrumentation}

The non-verbal measure of emotional response, the Self-Assessment Manikin $(\mathrm{SAM})^{87}$ and $\mathrm{AdSAM}^{\circledR},{ }^{88}$ which visually measures the dimensions of PAD with a graphic character arrayed along a continuous 9-point scale, was used in 
Table 1: Descriptive statistics of measurement items: mean, standard deviation and responses

\begin{tabular}{lllll}
\hline Group & Variable & Mean & SD & N \\
\hline Cognitive elaborators & Pleasure & 7.20 & 1.61 & 113 \\
& Arousal & 6.22 & 2.10 & 113 \\
& Dominance & 6.19 & 1.93 & 113 \\
& Purchase intent & 3.52 & 1.02 & 113 \\
Cognitive misers & Pleasure & 6.43 & 1.95 & 141 \\
& Arousal & 5.80 & 2.48 & 141 \\
& Dominance & 5.69 & 2.31 & 141 \\
& Purchase intent & 3.08 & 1.07 & 254 \\
\hline
\end{tabular}

this study. The PAD bipolar dimensions consist of pleasure/displeasure, arousal/non-arousal and dominance/submissiveness. These dimensions adequately describe the full spectrum of human emotions. They have been reliably measured and are sufficient to define all emotional states. ${ }^{89}$ PAD has gained popularity due to its simplicity and the ability to cover the full range of human emotions. ${ }^{90}$

The use of $\operatorname{AdSAM}^{\circledR}$ as an instrument helped to overcome problems associated with cumbersome and time-consuming verbal self-report measures. SAM and AdSAM $^{\circledR}$ were developed to adequately represent Russell and Mehrabian's PAD. It uses a graphic character that eliminates much of the biases associated with verbal and other non-verbal measures. ${ }^{91}$ The graphic character is easily understood and identifiable by both adults and children. ${ }^{92}$ In addition, SAM reduces respondent wear-out and is not limited by age, gender, culture or language differences. ${ }^{93}$ AdSAM $^{\circledR}$ has also proven to be an effective and efficient instrument to determine emotional responses to advertisements ${ }^{94}$ and, most importantly, it accurately measures the respondents' feelings to an advertisement. ${ }^{95}$

In these copy tests of a mini-campaign of two car advertisements, $\operatorname{AdSAM}^{\circledR}$ was placed near the beginning of the interview. After respondents were asked a series of three recall questions, they were then asked to identify their feelings associated with the test commercial using AdSAM ${ }^{\circledR}$, Using this non-verbal process, respondents were asked to indicate 'how the commercial made them feel'. On average, they took from 15 to 30 seconds to answer.

\section{RESULTS}

\section{Descriptive statistics}

The results from the comparison of the two groups, cognitive elaborators and cognitive misers, were obtained by examining for differences among four measured dependent variables. The descriptive statistics are shown in Table 1.

The descriptive statistics in Table 1 provide an interesting insight into the variation of spontaneous reaction and show that the emotional reactions as measured by AdSAM's PAD score are consistently higher for the cognitive elaborators than for the cognitive misers. On all three major emotional dimensions (PAD) the cognitive elaborators have higher mean scores than the cognitive misers. The mean scores were converged on a 9-unit bipolar scale.

\section{Tests of hypotheses: Emotional core of cognition}

The first hypothesis $\left(\mathrm{H}_{1}\right)$ stated that the emotional response of the cognitive 


\section{Cognitive elaborators}

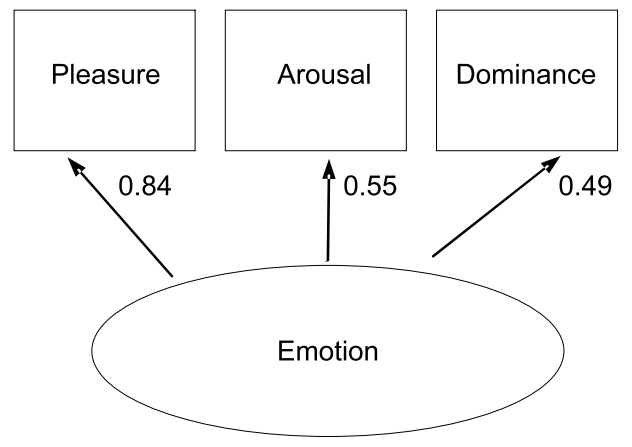

Cognitive misers

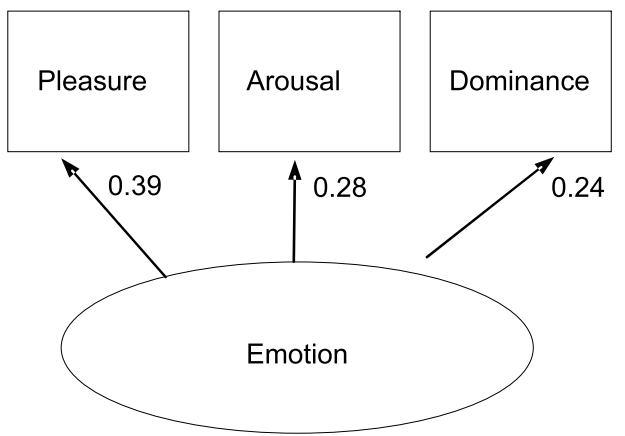

Figure 1 Multi-group LISREL measurement model with standardised factor loadings

Table 2: LISREL goodness-of-model-fit test statistics

\begin{tabular}{lll}
\hline & \multicolumn{2}{l}{ SRMR-CFI LISREL Model fit criteria } \\
& Group SRMR $(<\mathbf{0 . 0 9 )}$ & CFI (>0.95) \\
\hline Cognitive elaborators & 0.07 & 0.91 \\
Cognitive misers & 0.00 & 1.00 \\
\hline
\end{tabular}

SRMR-CFI, standardised root mean square residual and comparative fit index; CFI, comparative fit index

elaborators would be significantly greater than that of the cognitive misers. To test this hypothesis, a multi-group LISREL measurement model and a multivariate analysis of variance (MANOVA) were conducted.

As shown in Figure 1 and Table 2, the emotional responses are highly loaded on cognitive elaborators and cognitive misers and meet the goodness-of-model-fit criteria. ${ }^{96}$ In addition, the likelihood ratio test (LRT), using chi-square statistics, endorses the idea that the cognitive elaborators have significantly higher emotional loading than the cognitive misers. ${ }^{97}$

For the MANOVA result to be valid, several underlying assumptions were checked prior to interpretation. These assumptions included multivariate normality, linearity among dependent variables and equal variance for independent group. ${ }^{98}$ The normality was checked on each six marginal distribution using both Shapiro-Wilk test statistics $(N<2,000)$ for normality and visual normal QQ plot inspection. The sample data generally trended the straight 
Table 3: The effects of SR group (elaborators vs misers) on the linear combination of pleasure, arousal and dominance

\begin{tabular}{llrl}
\hline Analysis & Dependent variable & $\boldsymbol{F}$ & $\boldsymbol{p}$-value \\
\hline MANOVA & Pleasure-arousal-dominance & $3.98(\mathrm{df}=3$, Wilk's $\lambda=0.95)$ & 0.01 \\
ANOVA & Pleasure & $11.49(\mathrm{df}=1)$ & 0.00 \\
& Arousal & $1.89(\mathrm{df}=1)$ & 0.17 \\
& Dominance & $2.96(\mathrm{df}=1)$ & 0.09 \\
ANOVA & Purchase intention & $23.39(\mathrm{df}=1)$ & 0.00 \\
\hline
\end{tabular}

MANOVA, multivariate analysis of variance; ANOVA, analysis of variance.

Table 4: Pleasure, arousal and dominance simple unstructured regression on the purchase intention

\begin{tabular}{lllll}
\hline Group & Indicator & $\boldsymbol{B}$ & $\boldsymbol{t}$-statistics & $\boldsymbol{p}$-value \\
\hline Cognitive SR & Pleasure & 0.04 & 0.64 & 0.53 \\
& Arousal & 0.02 & 0.49 & 0.63 \\
Affective SR & Dominance & 0.15 & 2.80 & 0.01 \\
& Pleasure & 0.18 & 3.62 & 0.00 \\
& Arousal & 0.00 & 0.01 & 0.99 \\
& Dominance & 0.00 & 0.04 & 0.97 \\
\hline
\end{tabular}

$\mathrm{SR}$, simple unstructured regression.

diagonal line of QQ plot showing normality. The multivariate and univariate homoscedasticity calculated through Box's $M(M=22.86, p=0.00)$ and Levene's test statistics $(F=2.82-6.77, p=0.04-0.10)$ asserted unequal variance in some dependent variables; however, any erratic shape or trends was not found in residual plot inspection and, moreover, group cell sizes were sufficiently balanced. ${ }^{9}$

Bartlett's test of sphericity $\left(\chi^{2}=74.6\right.$, $p=0.00)$ was significant at the 0.05 significance level and implies that there is a linear relationship among the PAD-dependent variables.

Table 3 shows the MANOVA and subsequent analysis of variance (ANOVA) analysis results. After linearly

decomposing the effects, a significant main effect of spontaneous response grouping was found at the 0.05 significance level (Wilk's $\lambda \simeq F=3.98$, $p<0.05$ ). As per the analysis (see Table 2 ), the cognitive elaborators show a significantly higher level of pleasure $(p<0.05)$ than the cognitive misers, and, although not significantly different, the means scores on arousal and dominance were higher for the cognitive elaborators than for the cognitive misers. The results of the MANOVA and the LISREL model confirm the hypothesis that the cognitive elaborators do indeed show a significant level of response over the cognitive misers.

\section{Tests of hypotheses: Explanatory power of affect}

$R Q_{2}$ and $H_{2}$ suggest that affect may have a great influence on the purchase intention of a consumer in the attitude change process. As shown in Figure 2, the path coefficient of the cognitive misers is greater than that of cognitive elaborators.

To locate the origin of explanatory power of affect in LISREL, a supplementary simple regression analysis was performed ${ }^{100}$ for each factor of emotion, namely PAD (Table 4). The results show that pleasure and dominance are the significant indicator variables for the explanatory power of affect (cognitive misers) as well as cognition (cognitive elaborators). Previous research results have indicated that emotional 
Cognitive elaborators

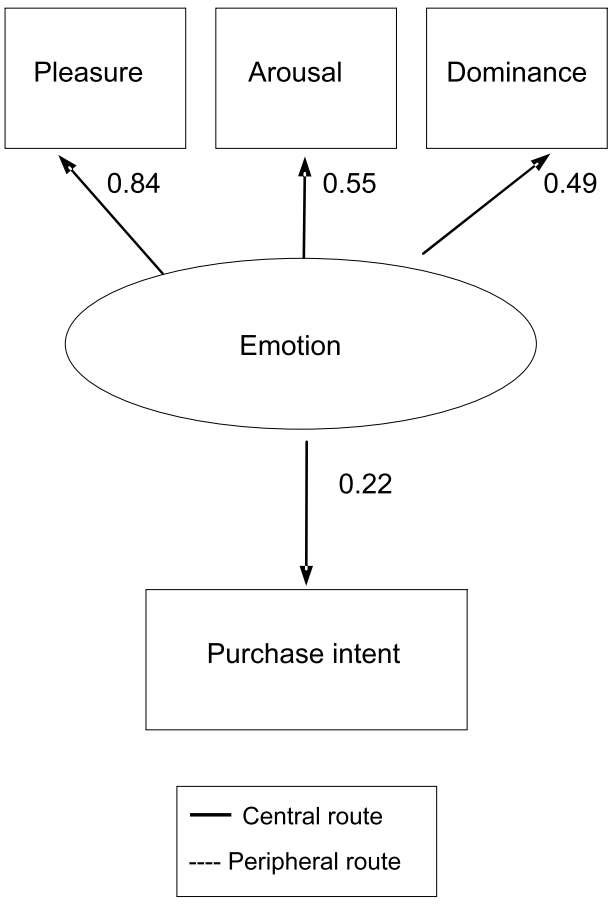

Cognitive misers

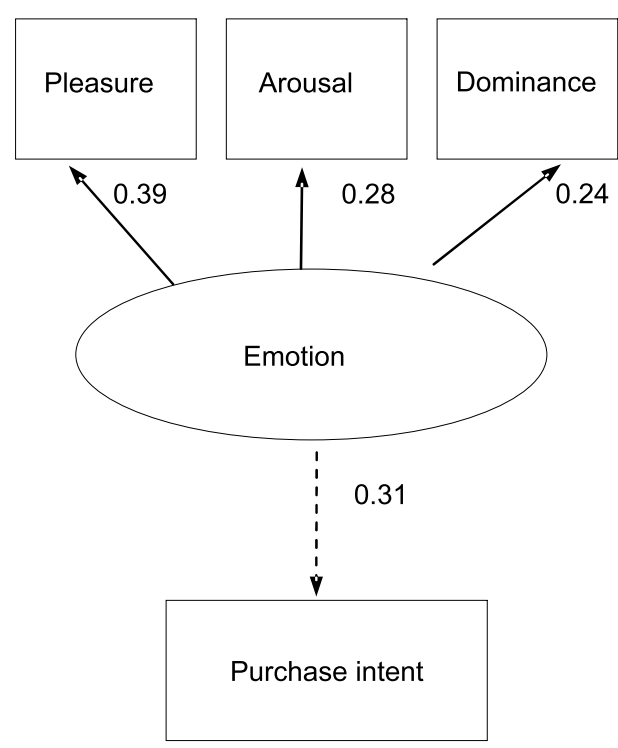

Figure 2 Multi-group LISREL hybrid model with standardised factor loadings and path coefficients

reactions influenced both central (systematic) and peripheral (heuristic) processing, specifically, positive emotions influenced affective peripheral information processing and negative emotions influenced cognitive central processing. ${ }^{101-104}$ In this case, the more systematic group, the cognitive elaborators, emoted more than the heuristic group, the cognitive misers. This supports the contention that cognition and affect are an important part of evaluation and decision making, and even those individuals who focus on the more cognitive information might be the same group that also reacts viscerally to the stimulus.

\section{Tests of hypotheses: Emotion and purchase intention}

To test $\mathrm{H}_{2}$, that emotional response and purchase intent are directly related to each other and thus, that the higher the PAD scores, the higher the purchase intent of that group, an additional ANOVA analysis on the purchase intention was annexed to the previous MANOVA and confirmatory factor analysis results. According to the ANOVA analysis result (see Table 3), the cognitive elaborators (3.52 mean purchase intention) would be more likely to contact a dealer than the cognitive misers (3.08 mean purchase intention). This result was shown to be of statistical significance (see Table 2, $p<0.05)$. Hence, $\mathrm{H}_{2}$ was supported because the cognitive elaborators, which showed a higher emotional response to the commercial, also showed a higher PI.

Figure 3 illustrates that the cognitive elaborators' responses have a more emotional core compared with the cognitive misers. The cognitive 
Cognitive elaborators

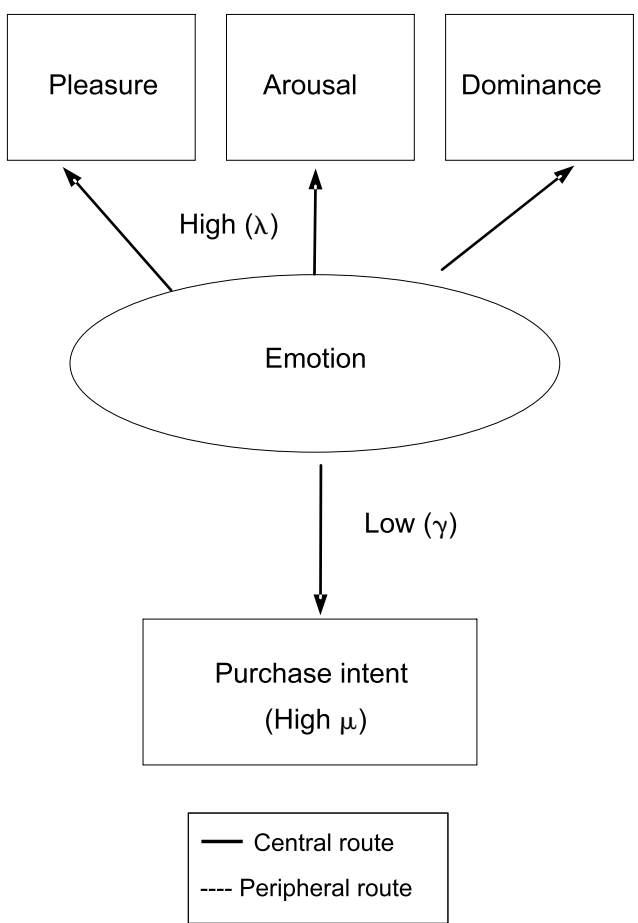

Cognitive misers

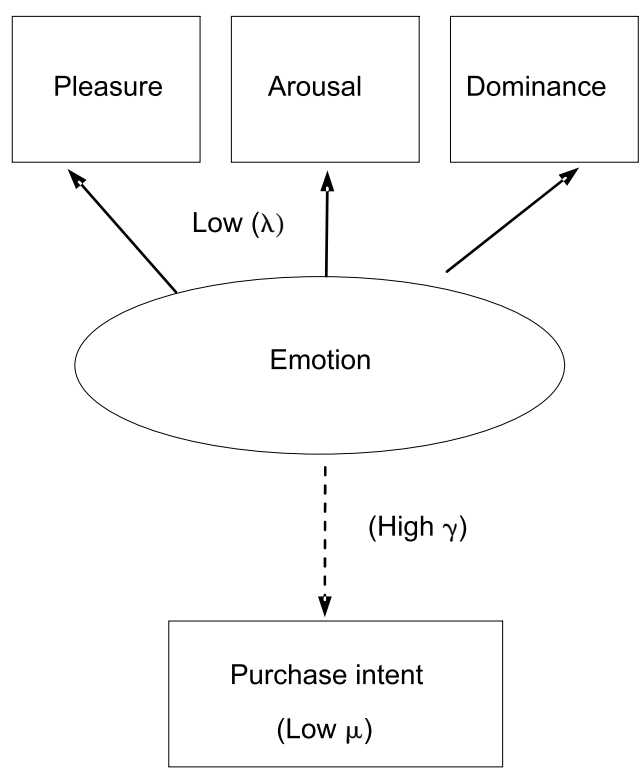

Figure 3 Significant relative loading and path patterns of structural equated ELM

elaborators also have a higher purchase intention score than cognitive misers. Consequently, the elaborators, or those who are said to have selected the more direct route to persuasion, have a higher emotion loading and purchase intention score than the misers or those who are said to have chosen the peripheral route to persuasion.

The enlightened consumer's purchase intention fluctuated with the degree of emotion, and the PAD scores were higher for those citing product features rather than those citing executional variables. This is in contrast to the theory of direct and peripheral route to persuasion as outlined by the ELM. After the respondents were exposed to the commercials, affective reaction showed a strong link to purchase intent, but was stronger in the cognitive elaborators group.

\section{DISCUSSION}

This study has found that affect is more than just a peripheral occurrence in the process of persuasion as suggested in the ELM. Indeed, the results contradict the notion that affect is the product of peripheral cues in the advertisement execution more than the factual information related to the product. According to the ELM those respondents who focus on the style of the commercial, the cognitive misers, would have the stronger emotional responses (but lower purchase intent) than the cognitive elaborators. The cognitive misers who focused on the commercial style rather than the product attributes did have lower purchase intent scores but they also had lower PAD scores upon seeing the commercials. It was the cognitive elaborators who had higher PAD scores as well as higher purchase intent scores. 
The results of the data analysis give further insight ${ }^{105}$ into the role of emotions in the process of persuasion. In fact, there is some suggestion in the discussion of the ELM that a higher affective response would interfere with the cognitive processing and therefore produce lower persuasion scores. ${ }^{106}$ The acceptance of the two hypotheses in this study demonstrates that cognitive processing has an emotional core. Of interest is the fact that the more cognitive group, the cognitive elaborators, shows significantly higher pleasure responses than the less cognitive group, the cognitive misers. A higher purchase intent accompanies this increase in pleasure. These results give an insight into the importance of affect and suggest that the ELM should be refined to include the role of emotions in the direct route to persuasion and the relationship of affect to behavioural intent.

The measurement model conducted between the two groups reveals a significant presence of affect in the cognitive elaborators. This demonstrates that even though information is being processed cognitively, the procedure is not being conducted in an emotional vacuum. These traces of emotion in cognitive processing provide support for the necessity of re-examining the role of emotion in the ELM and not simply assigning it to a peripheral role.

Although significant differences were found for one emotional variable pleasure - the other two emotional variables, arousal and dominance, show higher mean scores in the cognitive elaborators group. This finding is interesting as it suggests that even in cognitive elaboration, there is a certain amount of emotional reaction and that this reaction is significantly different from the reactions of the supposedly more affective cognitive miser group.

The behavioural intentions measurement supports these findings.
Purchase intent is significantly higher for the cognitive elaborators than for the cognitive misers. Due to the cognitive elaborators showing a higher level of emotional response when compared with cognitive misers, the cognitive elaborators emote more and can be considered the higher emotional group. This would then support the hypotheses: cognitive elaborators may generate a higher emotional response than cognitive misers and purchase intent is related to emotional response; the higher emotional response, the stronger the purchase intention.

These hypotheses were based on research that gave evidence regarding the importance of affect, and as a result, it was extrapolated that this concept could not be kept on the periphery of the ELM. The data analysis seems to support this theory by providing significant proof of the existence of emotion in the cognitive sphere. In addition, by linking purchase intent with affect, support is also provided for an attitude change via an affective route that could be at the centre of the ELM. This is further support that emotional response is a strong driver of the intent

It is important to determine the emotional response as accurately as possible. AdSAM ${ }^{\circledR}$ is an excellent tool for measuring viewer's responses. AdSAM $^{\circledR}$ is a quick, valid and reliable method of testing, ${ }^{107-110}$ and it does so across cultures and ethnic groups, without the problem of subjective meaning or other biases. It is an excellent tool for dissecting emotional responses, and it provides invaluable insights that help to highlight the role of emotion in a persuasive setting such as television advertising.

\section{Limitations}

Although the limitations do not overshadow the findings, the sample used 
for the study was restricted to a certain demographic and product categories. This restricts generalisation of the results of this study beyond high-involvement, durable goods.

In addition, the data were recoded on the basis of simple rules specially devised for the purpose of the study. These rules may need to be modified in order to conduct a more in-depth analysis of the participant responses. Furthermore, the number of coders involved limited the coding procedure. The perception of the diverse responses may differ from coder to coder.

The purchase intent variable, too, can be considered a limitation as there is no actual proof that a respondent from the 'emotional' group actually did go through with the purchase.

\section{Suggestions for future research}

Future research may attempt to include different demographic groups as well as different media, such as print and radio, and also different types of products and campaigns within this framework. There are a multitude of products and product classes available that could be considered for research purposes. In addition, a more rigorous statistical analysis can be employed to reveal even more significant results between 'cognitive' and 'emotional' groups.

It would be interesting to conduct a study on other highly priced consumer goods that would require as considerable pre-purchase cognition on the part of the consumer and identify the amount of emotion involved in the purchase. To make this study even more intriguing, it could be worthwhile to ask a consumer the thoughts that went through their mind immediately prior to and after the high-price purchase. These responses could then be examined for their emotional content and this could help in identifying whether emotion or cognition was the main driving force behind the purchase.

The ELM is widely used in a number of disciplines and has increased in popularity ever since its inception because of its largely cognitive base that attempts to explain the persuasive power of a message in terms of thought elaboration. Thus, the ELM seems to be emphasising cognition over emotion in the process of persuasion. This study has attempted to show that the basic tenet that the ELM proposes may be incorrect and that affect needs to be given a much more significant role and not be kept on the periphery of the ELM.

Research in neuro scientific spheres has re-affirmed the importance of emotion, and the results of this study seem to support this research. It is hoped that this study will add further insight to the role that affect plays in a persuasive process.

\section{References}

1 Petty, R. E. and Cacioppo, J. T. (1986a) 'Communication and persuasion: Central and peripheral routes to attitude change', Springer-Verlag, New York, NY.

2 Lippmann, W. (1922) 'Public opinion', Macmillan, New York, NY.

3 Lasswell, H. (1927) 'Propaganda techniques in the World War', Peter Smith, New York, NY.

4 Petty, R. E. and Priester, J. R. (1994) 'Mass media attitude change: Implications of the elaboration likelihood model of persuasion' in Bryant, J. and Zillmann, D. (eds) 'Media effects: Advances in theory and research', Erlbaum, Hillsdale, NJ, pp. 91-122.

5 Hyman, H. H. and Sheatsley, P. B. (1947) 'Some reasons why information campaigns fail', Public Opinion Quarterly, Vol. 11, pp. 412-423.

6 Katz, D. and Lazarsfeld, P. R. (1955) 'Personal influence', Free Press, New York, NY.

7 Hovland, C.I., Lumsdaine, A. and Sheffield, F. (1949) 'Experiments on mass communication', Princeton University Press, Princeton, NJ.

8 Allport, G. (1935) 'Attitudes', in Murchison, C. (ed.) 'Handbook of social psychology', Clark University Press, Worcester, MA, p. 2.

9 Petty and Priester (1994) op. cit.

10 Kiesler, C. A., Collins, B. E. and Miller, N. (1969) 'Attitude change: A critical analysis of theoretical 
analyses', John Wiley and Sons, New York, NY.

11 Petty, R. E. and Cacioppo, J. T. (1996) 'Attitude and persuasion: Classic and contemporary approaches', Westview Press, Boulder, CO.

12 Insko, C. A. and Schopler, J. (1972) 'Experimental social psychology', Academic Press, New York, NY.

13 Petty and Cacioppo (1996) op. cit.

14 Morris, J. D., Woo, C. M., Geason, J. A. and Kim, J. (2002) 'The power of affect: Predicting intention', Journal of Advertising Research, Vol. 42 (May/June), pp. 7-17.

15 Corey, S. M. (1937) 'Professed attitudes and actual behavior', Journal of Educational Psychology, Vol. 28, pp. 271-280.

16 Lambert, J. (1980) 'Social psychology', Macmillan, New York, NY.

17 Fishbein, M. and Ajzen, I. (1974) 'Attitudes toward objects as predictors of single and multiple behavioral criteria', Psychological Review, Vol. 81, pp. 59-74.

18 Fishbein, M. and Ajzen, I. (1975) 'Belief, attitude, intention and behavior: An introduction to theory and research', Addison-Wesley, Reading, MA.

19 Ajzen, I. and Fishbein, M. (1977) 'Attitude-behavior relations: A theoretical analysis and a review of empirical research', Psychological Bulletin, Vol. 84, pp. 888-918.

20 Ajzen, I. and Fishbein, M. (1980) 'Understanding attitudes and predicting social behavior', Prentice Hall, Englewood Cliffs, NJ.

21 Fishbein and Ajzen (1975) op. cit.

22 Petty and Cacioppo (1986a) op. cit.

23 Ibid.

24 Ibid.

25 Petty, R. E., Cacioppo, J. T., Strathman, A. J. and Priester, J. R. (1994) 'To think or not to think: Exploring two routes to persuasion' in Shavitt, $\mathrm{S}$. and Brock, T. C. (eds) 'Persuasion: Psychological insights and perspectives', Allyn and Bacon, Boston, MA, pp. 113-147.

26 Petty and Cacioppo (1986a) op. cit.

27 Morris et al. (2002) op. cit.

28 Izard, C. E. (1991) 'The psychology of emotions', Plenum Press, New York, NY.

29 Mowrer, O. H. (1960) 'Learning theory and behavior', Wiley, New York, NY.

30 Neisser, U. (1967) 'Cognitive psychology', Prentice Hall, Englewood Cliffs, NJ.

31 Damasio, A. R. (1994) 'Descartes' error: Emotion, reason and the human brain', Grosset/Putnam, New York, NY, pp. 18-19.

32 Davidson, R. J. (2000) 'Cognitive neuroscience needs affective neuroscience (and vice versa)', Brain and Cognition, Vol. 42, pp. 89-92.

33 Nauta, W. H. (1971) 'The problem of the frontal lobe: A reinterpretation', Journal of Psychiatric Research, Vol. 8, pp. 167-187.

34 Damasio, A. R. (1989) 'The brain binds entities and events by multiregional activation from convergence zones', Neural Computation, Vol. 1, pp. 123-132.

35 Davidson (2000) op. cit.

36 Zajonc, R. B. (1984) 'On the primacy of affect',
American Psychology, Vol. 39, pp. 117-123.

37 Ledoux, J. E. (1995) 'Emotion: Clues from the brain', Annual Review of Psychology, Vol. 46, pp. 209-235.

38 Damasio (1994) op. cit.

39 Damasio, A. R. (1999) 'The feeling of what happens: Body and emotion in the making of consciousness', Harcourt Brace, New York, NY, pp. 41-61.

40 Davidson (2000) op. cit.

41 Tooby, J. and Cosmides, L. (1990) 'The past explains the present: Emotional adaptations and the structure of ancestral environments,' Ethology and Sociobiology, Vol. 11, pp. 375-424.

42 Ledoux (1995) op. cit.

43 Davidson (2000) op. cit.

44 Cohen, J. B. (1990) 'Attitude, affect and consumer behavior' in Moore, B. S. and Isen, A. M. (eds)

'Affect and social behavior', Cambridge University Press, Cambridge, UK, pp. 152-206.

45 Petty and Cacioppo (1996) op. cit.

46 Ibid.

47 Ibid.

48 Belch, G. E. and Belch, M. A. (1998) 'Advertising and promotion: An integrated marketing

communications perspective', 4th edn, McGraw-Hill, New York. NY.

49 Lavidge, R. C. and Steiner, G. (1961) 'A model for predictive measurements of advertising effectiveness', Journal of Marketing, Vol. 25 (October), pp. 59-62.

50 Ibid.

51 Krugman, H. E. (1965) 'The impact of television advertising: Learning without involvement', Public Opinion Quarterly, Vol. 29, pp. 349-356.

52 Houston, M. J. and Rothschild, M. L. (1978) 'Conceptual and methodological perspectives on involvement' in Jain, S. C. (ed.) 'Research frontiers in marketing: Dialogues and directions', American Marketing Association, Chicago, IL, pp. 184-187.

53 Vaughn, R. (1983) 'How advertising works: A planning model', Journal of Advertising Research, Vol. 23, pp. 22-28.

54 Petty, R. E., Cacioppo, J. T. and Schumann, D. W. (1983) 'Central and peripheral routes to advertising effectiveness: The moderating role of involvement', Journal of Consumer Research, Vol. 10, pp. 134-148.

55 Preston, I. L. (1982) 'The association model of the advertising communication process', Journal of Advertising, Vol. 11, No. 2, pp. 3-15.

56 McGuire, W. J. (1985) 'Attitudes and attitude change' in Lindzey, G. and Aronson, E. (eds) 'Handbook of social psychology', 3rd edn, Random House, New York, NY, p. 2, pp. 233-346.

57 McGuire, W. J. (1989) 'Theoretical foundations of campaigns' in Rice, R. E. and Atkin, C. K. (eds) 'Public communication campaigns', 2nd edn, Sage, Newbury Park, CA, pp. 43-65.

58 Petty, R. E., Baker, S. M. and Gleicher, F. (1991) 'Attitudes and drug abuse prevention: Implications of the Elaboration Likelihood Model of persuasion' in Donohew, L., Sypher, H. E. and Bukoski, W. J. (eds) 'Persuasive communication and drug abuse 
prevention', Erlbaum, Hillsdale, NJ, pp. 71-90.

59 Petty and Priester (1994) op. cit.

60 Greenwald, A. G. (1968) 'Cognitive learning, cognitive response to persuasion, and attitude change' in Greenwald, A. G., Brock, T. and Ostrom, T. (eds) 'Psychological foundations of attitudes', Academic Press, New York, NY, pp. $147-170$.

61 Petty, R. E., Ostrom, T. M. and Brock, T. C. (1981) 'Cognitive responses in persuasion', Erlbaum, Hillsdale, NJ.

62 Petty and Priester (1994) op. cit.

63 Petty and Cacioppo (1996) op. cit.

64 Taylor, S. E. (1981) 'The interface of cognitive and social psychology' in Harvey, J. H. (ed.) 'Cognition, social behavior and the environment', Erlbaum, Hillsdale, NJ.

65 Petty and Cacioppo (1996) op. cit.

66 Damasio (1999) op. cit.

67 Ledoux (1995) op. cit.

68 Davidson (2000) op. cit.

69 Morris et al. (2002) op. cit.

70 Petty et al. (1994) op. cit.

71 Batra, R. and Staynman, D. M. (1990) 'The role of mood in advertising effectiveness', Journal of Consumer Research, Vol. 17, pp. 203-214.

72 Bohner, G. and Apostolidou, W. (1994) 'Mood and persuasion: Independent effects of affect before and after message processing, Journal of Social Psychology, Vol. 134, pp. 707-709.

73 Bohner, G., Chaiken, S. and Hyundadi, P. (1994) 'The role of mood and message ambiguity in the interplay of systematic and heuristic processing', European Journal of Social Psychology, Vol. 24, pp. 207-221.

74 Kuykendall, D. and Keating, J. P. (1990) 'Mood and persuasion: Evidence for the differential influence of positive and negative states', Psychology and Marketing, Vol. 7, pp. 1-9.

75 Chaiken, S. and Maheswaran, D. (1994) 'Heuristic processing can bias systematic processing: Effects of source credibility, argument ambiguity, and task importance on attitude judgment', Journal of Personality and Social Psychology, Vol. 66, pp. 460-473.

76 Edens, K. M. and McCormick, C. B. (2000) 'How do adolescent process advertisements? The influence of ad characteristics, processing objective and gender', Contemporary Educational Psychology, Vol. 25, pp. $450-463$.

77 Ibid.

78 Petty and Cacioppo (1986a) op. cit.

79 Ibid.

80 Holsti, O. R. (1969) 'Content analysis for the social sciences and humanities', Addison-Wesley Publishing, Reading, MA.

81 Vaughn (1983) op. cit.

82 Petty, R. E. and Cacioppo, J. T. (1986b) 'The elaboration likelihood model of persuasion' in Berkowitz, L. (ed) 'Advances in experimental social psychology (Vol. 19)', Academic Press, New York, NY, pp. 123-205.

83 Hoyer, W. D. and Maclnnis, D. J. (2004) 'Consumer behavior', 3rd edn, Houghton Mifflin, Boston, MA, p. 57.

84 Cacioppo, J. T., Petty, R. E., Kao, C. F. and

Rodriguez, R. (1986) 'Central and peripheral routes to persuasion: An individual difference perspective', Journal of Personality and Social Psychology, Vol. 51,

No. 5, pp. 1032-1043.

85 Ibid.

86 Ibid.

87 Lang, P. J. (1980) 'Behavioral treatment and bio-behavioral assessment: Computer applications' in Sidowski, J. B., Johnson, J. H. and Williams, T. A. (eds) 'Technology in mental health care delivery systems', Ablex, Norwood, NJ, pp. 119-137.

88 Morris, J. D., Bradley, M. M., Waine, C. A. and Lang, J. B. (1992) 'Assessing affective reactions to advertisements with the self-assessment manikin (SAM)'. Paper presented at Southern Marketing Association Conference.

89 Mehrabian, A. and Russell, J. A. (1977) 'Evidence of a three-factor theory', Journal of Research in Personality, Vol. 11, pp. 273-294.

90 Havlena, W. J. and Holbrook, M. B. (1986) 'The varieties of consumption experience: Comparing two typologies of emotion in consumer behavior', Journal of Consumer Research, Vol. 13, pp. 394-404.

91 Morris, J. D. and Waine, C. A. (1993) 'Managing the creative effort: Pre-production and post-production measures of emotional' in Thorson, E. (ed.) 'Proceedings of the 1993 Conference of the American Academy of Advertising', Columbia, MO, pp. 158-176.

92 Morris, J. D., Woo, C. M. and Cho, C.-H. (2003) 'Internet measures of advertising effects: A global issue', Journal of Current Issues and Research in Advertising, Vol. 25 (Spring), pp. 27-43.

93 Morris and Waine (1993) op. cit.

94 Morris et al. (1992) op. cit.

95 Morris et al. (2003) op. cit.

96 Jreskog, K. G. and Srbom, D. (1997) 'LISREL 8: Structural equation modeling with the SIMPLIS command language', Scientific Software International, Chicago, IL.

97 Embretson, S. E. and Reise, S. P. (2000) 'Item response theory for psychologists', Lawrence Erlbaum Associates, Mahwah, NJ.

98 Hair, J. F. Jr, Anderson, R. E., Tatham, R. L. and Black, W. C. (1998) 'Multivariate data analysis', 5th edn', Prentice Hall, Upper Saddle River, NJ.

99 Johnson, R. A. and Wichern, D. W. (1992) 'Applied multivariate statistical analysis, 3rd edn', Prentice Hall, Englewood Cliffs, NJ.

100 Rawlings, J. O., Pantula, S. G. and Dickey, D. A. (1998) 'Applied regression analysis: A research tool', 2nd edn', Springer-Verlag, New York, NY.

101 Batra and Staynman (1990) op. cit.

102 Bohner and Apostolidou (1994) op. cit.

103 Bohner et al. (1994) op. cit.

104 Kuykendall and Keating (1990) op. cit.

105 Morris et al. (2002) op. cit.

106 Petty and Cacioppo (1986a) op. cit. 
107 Lang (1980) op. cit.

108 Morris et al. (1992) op. cit.

109 Morris and Waine (1993) op. cit.

110 Morris et al. (2002) op. cit.

\section{APPENDIX A: ADVERTISEMENTS}

Commercial 1: 'Listen'. This commercial compares the sedan with its European counterpart by letting the owner of the European counterpart car test drive the sedan on a mountain road. The extensive branding of the make and model throughout the execution emphasise the name of the sedan. The performance of the sedan thoroughly impresses the European car owner and the commercial focuses on the low price of the sedan by communicating it as a 'whisper' between friends. The overall effect of the commercial is to provide a perception of affordability without offering a sticker price.

Commercial 2: 'Side Road'. This commercial communicates a more focused message of performance and handling of the sedan. By using descriptions of the sedan's engine and creating an exciting imagery of performance coupled with upbeat music, the commercial attempts to communicate the superiority of the sedan as compared with its European counterparts. The commercial concentrates on the facets of a comfortable, safe and secure ride and various useful features to make its case for the sedan. Affordability is indicated too, but not to the extent that it was in the first commercial. The overall effect of the commercial is to generate overall positive imagery for the sedan.

\section{APPENDIX B: COPYTESTED VARIABLE SET}

Variables tested in isolated re-exposure to sedan commercials:
- main ideas

- spontaneous reactions (thoughts and feelings)

- elements found confusing

- elements found hard to believe

- $\operatorname{AdSAM}^{\circledR}$

- likes/dislikes

- commercial profile - a battery of attributes designed to get at the tonality of the commercials

- overall commercial rating

- uniqueness of message

- overall sedan rating

- image scan - a battery of attributes designed to determine whether explicit or implicit objectives are being communicated

- increased interest rating

- visitation intent

- driver profile

- slogan/tagline evaluation

- character evaluation

- music evaluation

- overall profile battery

- vehicle ownership

\section{APPENDIX C: ADSAM ${ }^{\circledR}$}

The structural model of LISREL indicates that although motivated (intends to purchase a new, not used, vehicle from a qualifying vehicle set within the next two years) ability (age 35-54 years with $\$ 50,000+$ household income) sample respondents see relevant (must be principal driver and primary/shared decision maker of 1992 or newer vehicle, bought new) car (high involvement/think product category in Foote Cone \& Belding [FCB] quadrant) ad message, they strongly followed big and wide peripheral route to purchase intention. The peripheral affective route is not always peripheral per se in the ELM and it becomes the central message. $^{76}$ 
Morris, Woo and Singh

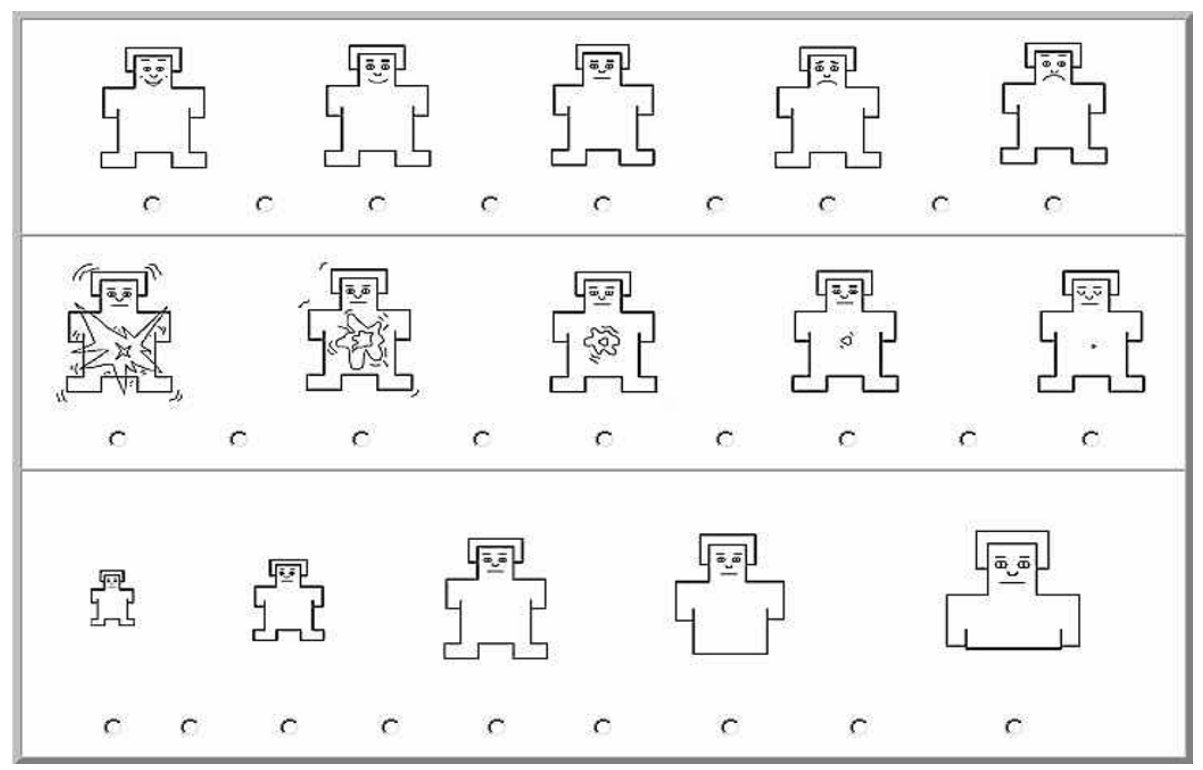

Figure A1 AdSAM $^{\circledR}$ 